OPEN ACCESS

Edited by:

Roy Brouwer,

University of Waterloo, Canada

Reviewed by:

Clara Manno,

British Antarctic Survey (BAS),

United Kingdom

Stephen James Malcolm,

Centre for Environment, Fisheries and

Aquaculture Science (CEFAS),

United Kingdom

*Correspondence:

Jana Stoever

stoever@economics.uni-kiel.de

Specialty section:

This article was submitted to

Marine Pollution,

a section of the journal

Frontiers in Marine Science

Received: 23 February 2021

Accepted: 24 June 2021

Published: 23 July 2021

Citation:

Stoever J, Rehdanz K and Okoli IC (2021) A Drop in the Ocean: Patchy

Evidence on the Societal Benefits of Marine Litter Reduction.

Front. Mar. Sci. 8:671326.

doi: 10.3389/fmars.2021.671326

\section{A Drop in the Ocean: Patchy Evidence on the Societal Benefits of Marine Litter Reduction}

\author{
Jana Stoever*, Katrin Rehdanz and Ikechukwu Charles Okoli \\ Institute for Environmental, Resource and Spatial Economics, Kiel University, Kiel, Germany
}

The benefits of marine litter reduction to society, which are mostly non-market ones, need to be valued and quantified in monetary terms to be included in cost benefit analyses required by the EU Marine Strategy Framework Directive. This article investigates the extent to which these benefits can be derived from existing studies. We review the available empirical evidence and analyze its key characteristics based on descriptive statistics. Comparing the availability of estimates with the requirements for the EU Member States, we find a striking mismatch between the data available and the information required, which cannot be alleviated by benefit transfer. This finding is valid for both, ex-ante and ex-post, evaluation attempts. We conclude that the evidence available at present is too patchy to derive country-wide policy implications to the extent necessary to comprehensively conduct the evaluations required by the Directive.

\section{Keywords: societal benefits, environmental valuation, marine litter, micro plastics, Marine Strategy Framework Directive, willingness to pay}

\section{INTRODUCTION}

Marine litter, defined as any persistent, manufactured or processed solid material discarded, disposed of or abandoned in the marine and coastal environment, is a serious threat to the marine environment and human-well-being (e.g., Cheshire et al., 2009). This has led to a number of initiatives on various levels, most prominently on the level of the European Union (EU). In 2008, the EU adopted the Marine Strategy Framework Directive (MSFD) ${ }^{1}$. The MSFD requires EU Member States to develop and implement marine strategies containing so-called programmes of measures to protect and preserve the marine environment. Marine litter is one of the eleven descriptors listed in Annex I of the MSFD. For marine litter, the good environmental status (GES) that needs to be achieved or maintained by 2020 has been defined as "properties and quantities of marine litter [that] do not cause harm to the coastal and marine environment"2. This definition includes both micro and macro litter ${ }^{3}$. However, the European Commission acknowledges that

\footnotetext{
${ }^{1}$ Directive 2008/56/EC of the European Parliament and of the Council of 17 June 2008 establishing a framework for community action in the field of marine environmental policy. Marine Strategy Framework Directive. Available online at: http://data.europa.eu/eli/dir/2008/56/oj

${ }^{2}$ Annex 1 of Directive 2008/56/EC.

${ }^{3}$ Commission Decision 2010/477/EU identifies four indicators for marine litter: (10.1.1) trends in the amount of litter washed ashore and/or deposited on coastlines, including analysis of its composition, spatial distribution and, where possible, source, (10.1.2) trends in the amount of litter in the water column (including floating at the surface) and deposited on the seafloor, including analysis of its composition, spatial distribution and, where possible, source (10.1.3) trends in the amount, distribution and, where possible, composition of micro particles (in particular micro plastics), (10.2.1) trends in the amount and composition of litter ingested by marine animals (e.g., stomach analysis).
} 
there are no agreed-upon baselines or thresholds for either macro or micro litter, which makes monitoring the progress toward GES difficult ${ }^{4}$.

In addition to that, measures to achieve the GES need to be assessed by examining their cost-effectiveness and by carrying out cost-benefit analyses $(\mathrm{CBA})^{5}$. This information is a prerequisite for the ex-ante decision whether to implement policies for marine litter reduction. Additionally, results of valuation studies can be used for an ex-post evaluation of measures already in place. While the costs of measures might be relatively easy to determine, for example in terms of forgone revenues, quantifying the associated benefits is more challenging. Challenges arise for example as the change in the marine biosphere (less marine litter) leads to changes in the ecosystems' provision of goods and services, which, in turn, affect humans. Further, the benefits, which are mostly non-market, need to be valued and quantified in monetary terms to conduct a $\mathrm{CBA}^{6}$. Furthermore, the results of any environmental valuation are context-dependent. As original research on the monetary benefits of specific measures is often time-consuming and costly, benefit transfer approaches can be used instead (Bateman et al., 2002). Benefit transfer consists of an analysis of information provided by a single valuation study or a group of studies from the existing literature to value similar goods and services in another context. There is, however, a large literature discussing the validity of environmental benefits transfer [such as Kaul et al. (2013)]. Various sources of errors exist that might affect the accuracy of transfers. Among these is the generalization error that occurs when there is little correspondence between the study site and the policy site e.g., in terms of geographical proximity.

In this paper, we investigate the extent to which the benefits of marine litter reduction can be derived from existing valuation studies to inform policy-decision making. The valuation studies examine how people's preferences are affected when there is a marginal change in the provision of a particular ecosystem good or service. They focus on the maximum a household would be willing to pay for an improvement in environmental conditions ${ }^{7}$. Importantly, exercises in environmental valuation do neither aim at valuing entire ecosystems nor do they produce measures of total economic value. Rather, they attempt to estimate the value of

\footnotetext{
${ }^{4}$ Report from the Commission to the European Parliament and the Council assessing Member States' monitoring programmes under the Marine Strategy Framework Directive (2008/56/EC), European Commission, 2017.

${ }^{5}$ For a detailed review of the economic requirements of the MSFD see COWI (2010).

${ }^{6}$ See Bertram and Rehdanz (2013) and Bertram et al. (2014) for a discussion related to the MSFD.

${ }^{7}$ We would like to highlight the difference between prices and values: Prices, which are mostly included in financial analyses, reflect only the part of an asset's value that is realized in markets. For most environmental goods and services there are either no functioning markets or no markets at all, and thus either prices that do not reflect their value or no prices at all. Environmental valuation offers a way to make explicit in monetary terms the benefit flows generated by natural capital stocks and the impacts of human decisions on these benefit flows. Please note that values are assigned to ecosystem services only insofar as they contribute directly or indirectly to human well-being. Environmental valuation is thus always based on an anthropocentric point of view.
}

a change in the provision of its goods and services, incorporating as many components of value as possible (Bateman et al., 2011).

In our investigation, we proceed in two steps. First, we review the current literature that addresses the societal benefits of reducing marine litter, limiting the scope of articles to those that provide quantitative assessments using environmental valuation techniques. This implies that values can be assigned to ecosystem services only insofar as they fulfill human needs or bring about satisfaction for humans and thus contribute directly or indirectly to human well-being. All studies in the sample use non-market valuation techniques to estimate benefits either using stated or revealed preference approaches ${ }^{8}$. We compare these studies, which all focus on marine litter and include plastic litter, in terms of their key characteristics. A particular focus of our analysis is on the willingness to pay (WTP) estimates.

Second, we combine the empirical evidence on the benefits of measures with the programmes of measures by the EU Member States. Using information on the European Commission's assessment of programmes of measures ${ }^{9}$, we highlight the focus of the Member States in terms of marine litter, in particular plastic litter, reduction. Based on this, we discuss the extent to which results of the valuation studies are able to inform policy.

The remainder of the paper is structured as follows: the next section provides a literature review of the valuation studies describing their similarities and differences. This is followed by a discussion of the valuation studies' results focusing on the benefits of marine litter reduction. The subsequent section combines the empirical evidence with the Member State's programmes of measures to discuss ex-ante and ex-post evaluation options. The final section concludes.

\section{EMPIRICAL EVIDENCE}

A list of potentially relevant studies was collected from the following computerized bibliographic databases (a) EconLit; (b) Web of Science Core; (c) Google Scholar; (d) National Ocean Economics Program; (e) Environmental Valuation Reference Inventory, and (f) Beneficial Use Values Database, since these databases provided the most relevant results during an initial explorative search phase ${ }^{10}$. We complemented the database search by examining the bibliographies of the relevant studies to find additional literature relevant to the review.

Using the search terms "beach litter", "marine litter", "willingness to pay", and "beach cleanliness" yielded over 30,000 studies, reports and other types of publications. After removing duplicates, we further narrowed down the results based on titles only. Of this reduced sample, we started a content-related evaluation based on the documents' abstracts. In the subsequent step, we excluded studies without any relevance to benefits of

\footnotetext{
${ }^{8}$ For an overview on the theory of the individual methods see Freeman et al. (2014). See TEEB (2010) for a discussion of their applicability, advantages, disadvantages, and limitations.

${ }^{9}$ Report from the Commission to the European Parliament and of the Council assessing Member States' programmes of measures under the Marine Strategy Framework Directive, COM/2018/562 final.

${ }^{10}$ The search and selection was carried out between 16th and 20th December 2019 and checked for updates in early March 2020.
} 
marine macro or micro litter removal or to improvement in the marine environment due to their removal from further analysis. The remaining studies were then assessed for eligibility on full texts, restricting our sample to studies that contain WTP estimates for marine litter control/removal. We, therefore, excluded studies that do not report WTP values from the review for a lack of comparability with the rest of the available studies [such studies are Morgan (1999), Ballance et al. (2000), Alves et al. (2014), and Krelling et al. (2017)]. We also excluded studies that investigate respondents' WTP for the removal of marine litter types other than the typical land and sea-based litter (plastics, butts, bottles, cans, bags, etc.). For example, we excluded the study by Zhai and Suzuki (2008), which investigates the benefits of removing garbage oil on the sea surface and sand beach from the review for being not comparable to other studies. We arrived at a sample of 22 publications included in the review (Table 1). See Figure A.1 in the Appendix for a detailed PRISMA statement.

The earliest study in our sample dates back to 1997 (Smith et al., 1997) and uses data sampled in 1992 in the USA. Subsequently, four studies were conducted around the start of the millennium and published ${ }^{11}$ between 1999 and 2008. Starting in 2012, the number of studies per year began to increase, with four studies having been published in 2013 and seven in 2018 alone. Since the specific year of publication may cluster to a certain effect randomly, looking at the year when the studies' data were collected adds some information about the robustness of this finding. Indeed, the survey year is more evenly distributed between the years with at least one study conducted per year since 2009 (except for 2012). This supports the observation that the empirical evidence has been gathered and published predominantly during the past decade (2009-2020).

Looking at the geographical coverage (Figure 1), the majority of studies focuses on sites in Europe (9) and Asia (7). Fewer studies are available for North America and the Carribean (5) South America (1) and Australia (1). The European studies cover sites in ten different countries and were published between 2002 and 2020. The Asian studies consist of a group of four studies in Turkey and a second group of more recent studies conducted in East and South East Asia, namely in South Korea, Pakistan, and China. Somewhat surprisingly, only two studies provide data for sites in the US. Overall, while many of the earlier studies focus on countries in Europe and Turkey, there is a broader coverage of countries and continents in recent years.

Turning to the location of litter that studies have considered, most studies focus solely on beach litter (12) or cover litter on beaches plus its surroundings (4). Three studies consider litter at the coast or in an archipelago area and explicitly include litter from boats. The remaining two studies focus on litter in the ocean (Choi and Lee, 2018) or in a river (Hanley et al., 2006) ${ }^{12}$.

The studies in the sample also vary by the type of (plastic) litter they cover. Most of the studies focus on macro litter (16). Four of these studies explicitly mention macro plastics, for the

\footnotetext{
${ }^{11}$ Apart from the conference paper by Ünal and Williams (1999), all other studies in the review have been published as journal articles (Table A.2 in the Appendix).

${ }^{12}$ One study (Enriquez-Acevedo et al., 2018) does not provide information on either the location or the type of litter considered.
}

others (12) we inferred from the study's description that the litter considered most likely includes macro plastics. The number of studies addressing micro litter is much lower. This is as expected as studies on the negative effect of micro litter are much more recent. Two studies capture both micro and macro litter, including macro and micro plastics, and one study investigates solely micro plastics (Choi and Lee, 2018). In the remaining three studies, the type of litter is not further specified.

\section{WILLINGNESS TO PAY FOR MARINE LITTER REDUCTION}

Studies reviewed differ in terms of the method used to elicit WTP (Table 1). The majority of studies used either a choice experiment (CE) or a contingent valuation (CV) design to elicit people's WTP for the removal of marine litter (12 and 11, respectively). Two of them use a combination of the two methods (Loomis and Santiago, 2013; Shen et al., 2019). Only one study in our sample applies the travel cost (TC) approach (Leggett et al., 2018).

The TC approach captures direct utility values based on revealed preferences, while the $\mathrm{CV}$ and the $\mathrm{CE}$ are able to cover use values as well as non-use values and are based on stated preferences (see Appendix A.3 in the Appendix for an overview of the different approaches in the marine context). Each of the valuation methods in our sample has characteristic advantages and disadvantages and may only be appropriate for valuing specific ecosystem goods and services ${ }^{13}$.

Turning to the number of WTP estimates, these vary between one and 54 per study with a median of six estimates per study. Figure 2 displays the total number of WTP estimates in our sample by valuation method. While the number of studies using either a CE or a CV design is almost the same, the total number of estimates for CV is much larger than for CE (123 and 85, respectively). This difference is mostly caused by one CV study providing 54 WTP estimates (Blakemore et al., 2002).

The studies' sampling strategies vary (for details see Table A.2 in the Appendix) with eight studies conducting on-site sampling, i.e., at beaches or nearby, and eleven studies using off-site sampling methods, i.e., approaching respondents at home (9) or at airports (2). The remaining three studies do not state where they collected their data. The earliest studies in our sample that collected their data online were the ones that took place in Sweden in 2009 (Östberg et al., 2012, 2013).

When classifying studies according to the type of respondent, 13 studies include only users in their sample. Few of these distinguish between visitors and residents in their analysis. The remaining nine studies include users as well as nonusers. This group consists of the five online studies and five offline studies. The decision to include or exclude non-users

\footnotetext{
${ }^{13}$ For example, stated preference studies use hypothetical surveys to elicit potential future changes. This might lead to the so-called hypothetical bias implying a difference between stated and revealed WTP values. However, the empirical evidence is mixed. For, a general discussion of the different methods' applicability, advantages, disadvantages and limitations is beyond the scope of this article. It can be found e.g., in TEEB (2010).
} 
TABLE 1 | Main characteristics of studies included in the review.

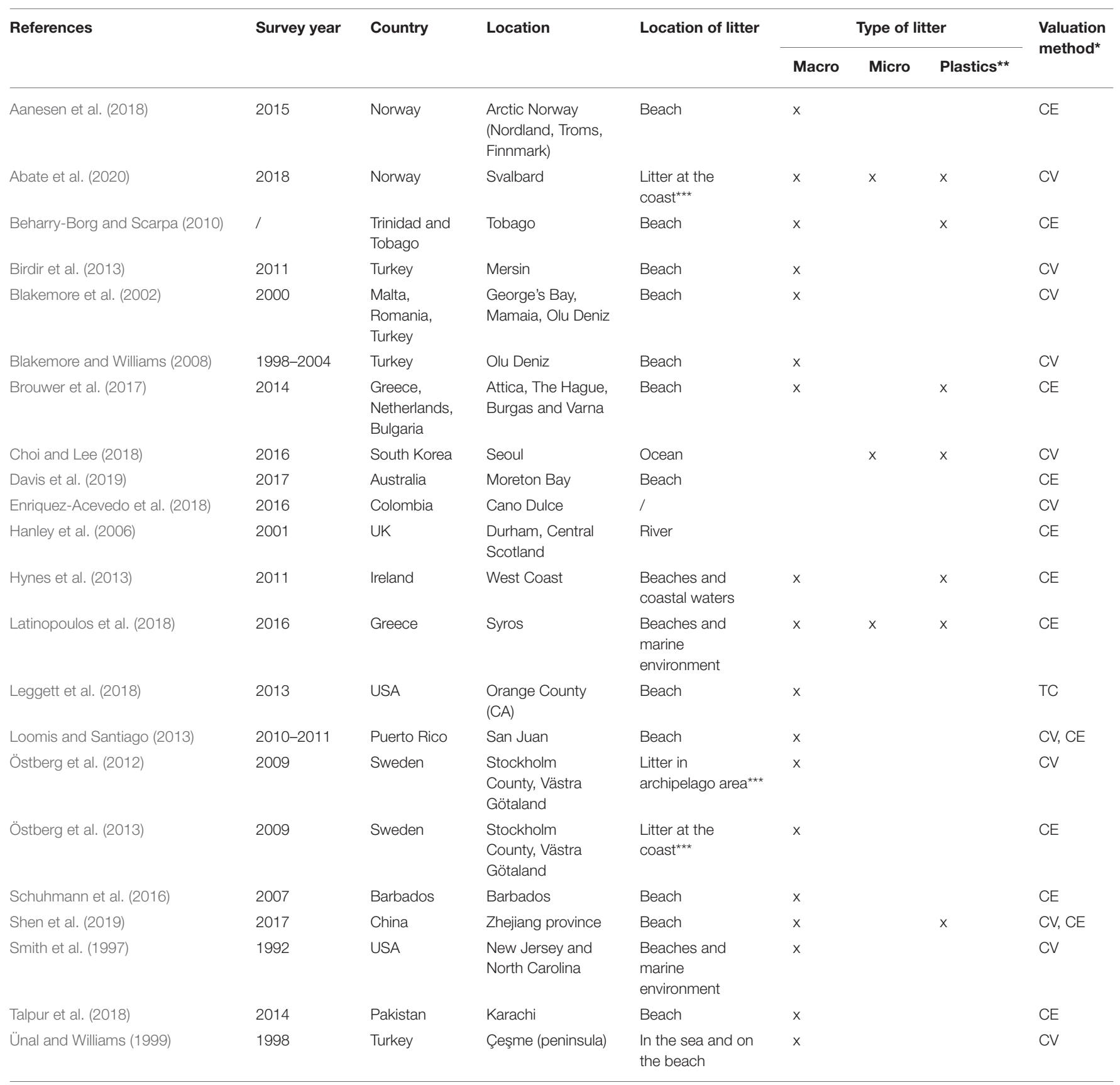

${ }^{*} \mathrm{CV}$, contingent valuation; $C E$, choice experiment; TC, travel cost; **study explicitly mentions plastic litter; ***litter from boats.

reflects the geographical focus of a study's research question. The majority of studies focuses on beach recreation for specific locations and hence focuses on users. Studies that include nonusers are typically much broader in geographical scope. The study sites of Östberg et al. (2013) or Abate et al. (2020), for example, cover hundreds of kilometers of the coast or a whole archipelago area.

Comparing the estimated WTPs, nine studies provide WTP estimates per person and trip (Figure 3) and twelve studies provide WTP estimates per person and year (Figure 4). To compare WTP estimates in terms of magnitude, we converted the reported WTP estimates to 2015 USD using official exchange rates and the deflator from the World Bank's World Development Indicators (World Bank, 2020). One study is omitted from this comparison: Schuhmann et al. (2016) report WTP as the price per room for a specific choice scenario. As information on the status quo is missing, we were unable to convert the price per room either into a 


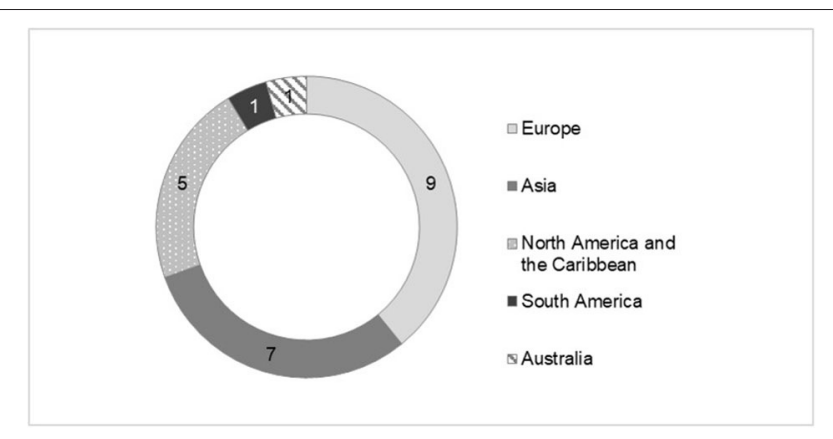

FIGURE 1 | Geographical Coverage: Number of studies, by continent. Many studies include several sites, but all of them are located on the same continent. The only exception is Blakemore et al. (2002), which includes study sites in both Europe (Malta, Romania) and Asia (Turkey). It was therefore assigned to both continents. All study sites in Turkey are located on the Asian continent and have been included accordingly.

WTP per person and trip or into a WTP per person and year $^{14}$.

The studies in the first set (Figure 3) report WTP estimates between 0 and 110 USD per person and trip, with a median value of 0.57 USD. All but one study provide estimates of a similar magnitude (between 0 and 10 USD per trip). The exception is Loomis and Santiago (2013), where the reported estimates are 105 and 110 USD per trip. In addition to the relatively small variation between the different studies' WTP estimates, the range of estimates for the individual studies, i.e., the width of the gray rectangle in Figure 3, is smaller than 6 USD for all studies.

Although the studies in the first set differ with respect to the location/country, sample size, their publication date and, importantly, in the methods they apply (CV, CE, TC), they also have some common features: Firstly, they focus on litter on the beach [only Ünal and Williams (1999) additionally include litter in the sea]. Secondly, all of the studies in this group are concerned with macro litter, plastics are mentioned in only two of them explicitly and none mentions micro plastics. Thirdly, all but one study in this group focus on users [only Talpur et al. (2018) interview users and non-users in Karachi/Pakistan] and all collect their data offline. Summarizing, we can conclude that users prefer cleaner sites with a reduction of macro plastics on (or near) the beach. The WTP per trip seems rather independent of the location/country and method applied.

The twelve studies in the second set (Figure 4) report WTP per person and year. The estimates range between a minimum of -18.50 USD and a maximum of 568.54 USD per person and year, with a median value of $34.67 \mathrm{USD}^{15}$. For all but one study, the median estimates lie between 1 and 70 USD per person and year [for Abate et al. (2020) the median WTP estimate is 307.42 USD].

\footnotetext{
${ }^{14}$ For completeness: When rates per night are multiplied by the average length of trip in the sample (nine nights) to calculate WTP values per trip, the resulting WTPs/WTAs range from -2061 to 2321 USD per trip with a median value of -858 USD.

${ }^{15}$ Note that the levels are not directly comparable between the sets, as the first set expresses its WTPs per trip and the second one per year.
}

Furthermore, the estimates vary a lot more within the individual studies (ranges between 0 and almost 500 USD) than in the first set of studies.

With respect to the method, this second set consists almost equally of CV and CE studies (five and seven, respectively), and includes studies published over the whole period and across all continents covered, with all but one (Enriquez-Acevedo et al., 2018) located in OECD countries. Respondents have been surveyed either at home or on the beach. The study areas covered are often larger than single beaches, e.g., archipelago areas, and the litter considered is located in the ocean, a river or in the marine environment in addition to being on the beach. Accordingly, the type of plastic litter covered by the studies in this set is also diverse: Two studies mention micro and macro plastics, two only macro and one only micro plastics ${ }^{16}$.

Comparing the two sets of studies, in the first set only one study elicits WTP for users and non-users (marked with an asterisk in Figure 3). In the second set, only four studies restrict their sample to users. The two sets of studies also differ in another characteristic, namely in the type of payment vehicles they employ. The first set includes a mix of different options. In five studies, the payment vehicle cannot be classified, as the authors either asked the respondents for their preferred mode of payment (Blakemore et al., 2002, Blakemore and Williams, 2008, and Birdir et al., 2013) or do not specify it (Ünal and Williams, 1999, Leggett et al., 2018). Note that Talpur et al. (2018) use both, additional travel costs and entry fees. The remaining studies in this set use either (entrance) fees (Beharry-Borg and Scarpa, 2010, Talpur et al., 2018, and Shen et al., 2019); additional travel costs (Loomis and Santiago, 2013, Talpur et al., 2018) or lodging prices (Schuhmann et al., 2016 is excluded from Figure 4). In contrast, the studies of the second set mostly use taxes as payment vehicle (7; for details, see Table A.2 in the Appendix). One study (Brouwer et al., 2017) uses different vehicles at different sites; a local tax in Greece and Bulgaria and an entrance fee in the Netherlands.

\section{ASSESSMENT OF EX-ANTE AND EX-POST EVALUATION OPTIONS}

In this section, we assess the availability of information on the benefits of marine litter reduction for policymaking. We first compare the stated foci of the MFSD Member States' programmes of measures with the availability of WTP estimates in these countries. We then assess the extent to which the existing valuation studies are able to inform policy in terms of the four MSFD indicators for marine litter. Finally, we discuss the applicability of the valuation studies for an ex-ante and ex-post evaluation of measures separately. We particularly address the question on the extent of information that was available prior to the implementation of measures and assess the ex-post evaluation options for measures already implemented.

\footnotetext{
${ }^{16}$ Most of the remaining studies are likely to include plastic litter (6) based on the studies' descriptions; for one study it cannot be inferred.
} 


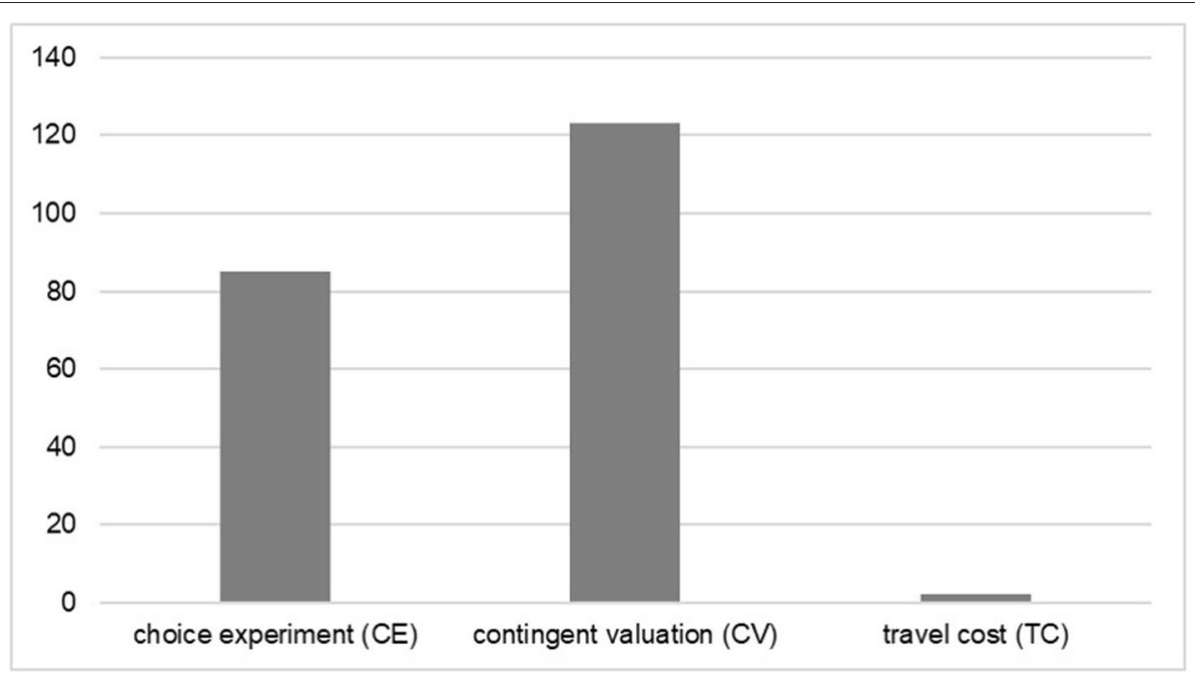

FIGURE 2 | Total number of WTP estimates, by method.

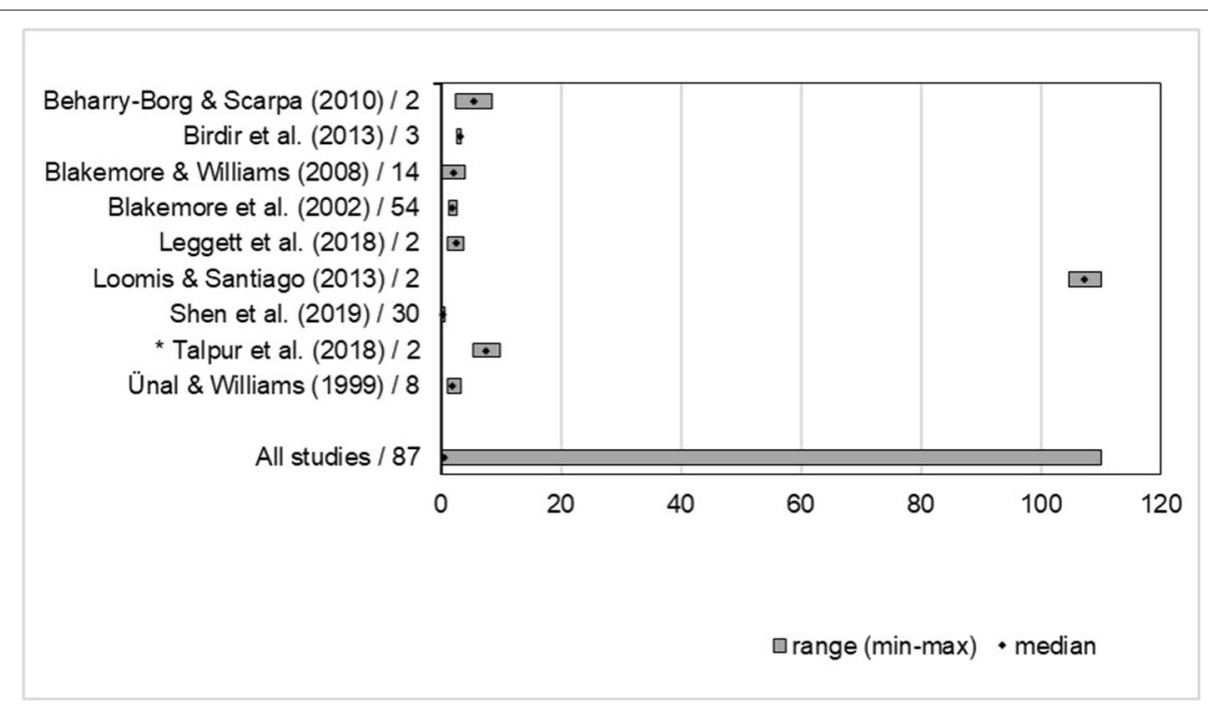

FIGURE 3 | Willingness to pay per person and trip by study (in 2015 USD). Bars show the range (min to max value) of estimated WTPs from each study, the diamonds represent the median WTP values. The number of coefficients in each study is reported next to the authors' names. An asterisk (*) denotes that a study includes users and non-users.

In 2018, the European Commission assessed the Member States' programmes ${ }^{17}$ in a report to the European Parliament and the Council (European Commission, 2018a). The report and the accompanying Staff Working Document (European Commission, 2018b) was updated in 2019 (European Commission, 2019) to cover countries that reported their national programmes after the cut-off date and could not be assessed in time for the initial report. Based on the information reported by the Member States, the assessment rates the programmes of measures in three categories: if they fully address,

${ }^{17}$ The MSFD requires its Member States to report their programmes of measures for achieving GES [Article 13(9) of Directive 2008/56/EC]. partially address or do not address the needs required to meet the MSFD targets and achieve GES, including its timeline. Table A.4 in the Appendix summarizes the results of the Staff Working Document (European Commission, 2019) for marine litter (descriptor 10). While all 23 Member States fully address macro litter, only ten fully address micro litter. Four Member States address micro litter indirectly and nine Member States do not address micro litter at all. Figure $\mathbf{5}$ summarizes these findings in panel A.

We use the results of the Commission's assessment and compare them with the results of our literature review, i.e., the extent to which (quantitative) information about the benefits of measures to reduce marine litter is available for the individual 


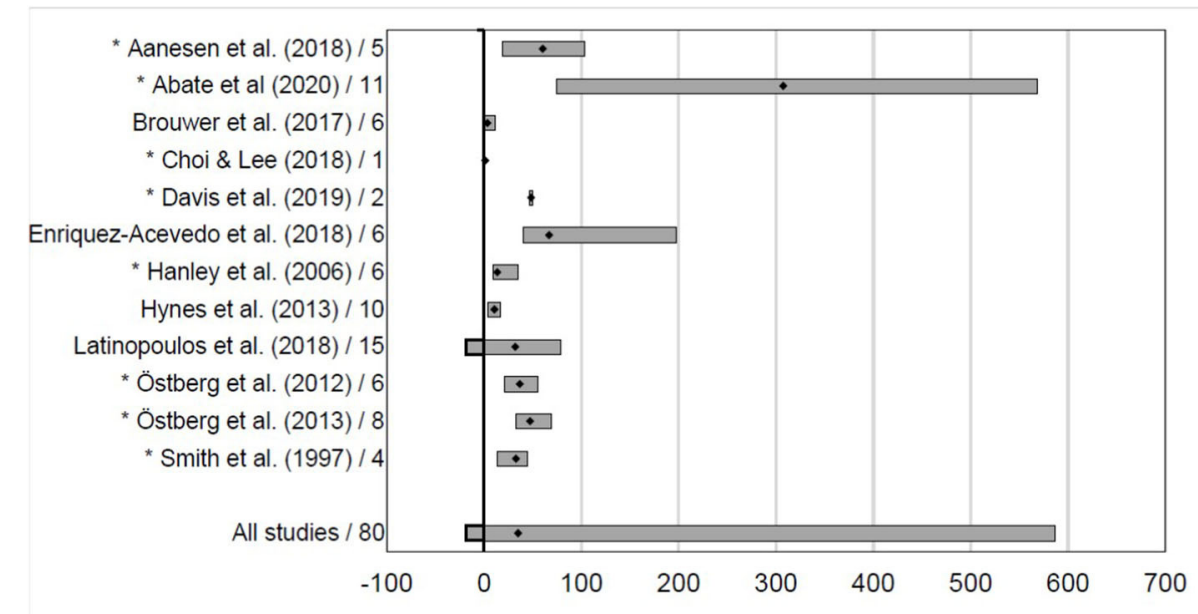

FIGURE 4 | Willingness to pay per person and year by study (in 2015 USD). Bars show the range (min to max value) of estimated WTPs from each study, the diamonds represent the median WTP values. The number of coefficients in each study is reported next to the authors' names. An asterisk (*) denotes that a study includes users and non-users.

countries. We find that seven studies provide WTP estimates for eight of the 23 Member States (Bulgaria, Greece, Ireland, Malta, the Netherlands, Romania, Sweden, and UK). Two studies focus on litter on beaches and can be linked to indicator 10.1.1 ${ }^{18}$. Two studies are related to indicator $10.1 .2^{19}$ covering coastal waters or the marine environment more generally. Further evidence is provided by two studies that focus on the coast or an archipelago area; one addresses litter from a river. Regarding the type of litter, it is apparent that the current valuation literature mostly relates to the indicator on macro litter (10.1.1); micro litter (indicator 10.1.3) is addressed by only one study. Figure 5 summarizes these findings in panel $\mathrm{B}$.

Combining information of both panels of Figure 5, of the eight countries for which benefit estimates are available, four fully address macro and micro litter in their programme of measures (Ireland, the Netherlands, Romania, and Sweden), while the other four fully address macro litter but do not address micro litter (Bulgaria, Greece, Malta, and the UK). As a first result, we can conclude that there is little agreement between the stated foci of the MSFD Member States' programmes of measures and the available WTP estimates in terms of the type of litter. Further, in terms of an ex-ante evaluation, information was available before $2016^{20}$ for only five countries, covering areas in Ireland (Hynes et al., 2013), Malta and Romania (Blakemore et al., 2002), Sweden

\footnotetext{
${ }^{18}$ Trends in the amount of litter washed ashore and/or deposited on coastlines, including analysis of its composition, spatial distribution and, where possible, source.

${ }^{19}$ Trends in the amount of litter in the water column (including floating at the surface) and deposited on the sea-floor, including analysis of its composition, spatial distribution, and where possible, source.

${ }^{20}$ Member States had to set up and implement programmes of measures to achieve GES in their marine waters by early 2016 (Art. 13 MSFD).
}

(Östberg et al., 2012, 2013), and the UK (Hanley et al., 2006). The information available was, therefore, insufficient for a broader exante evaluation of measures in terms of their benefits to society for all countries.

Investigating the relevance of the valuation studies for an ex-post evaluation of implemented measures, we find that for Ireland, the Netherlands, Romania and Sweden the scope of the valuation studies is narrower than the Commission's assessment, which covers macro and micro litter. Bulgaria, Greece, Malta and the UK are the only countries for which the valuation studies and the Commission's assessment coincide enabling an ex-post evaluation; all four countries focus on macro litter (see Figure 5) and provide WTP estimates for macro litter. Blakemore et al. (2002) estimate beach visitors' WTP to maintain or improve the beach of St. George's Bay, Malta. Litter is identified as the second important dislike of visitors next to noise and a lack of sand. The policy intervention is not further specified. The payment vehicle was not predefined, instead respondents were asked to state their preferred method of payment. The average WTP for different groups of respondents ranges between $£ 0.99$ and $£ 2.02$ per visit. Brouwer et al. (2017) estimate beach users' WTP for cleaner beaches for the two city beaches of Burgas and Varna in Bulgaria and two beaches in the larger Attica region of Greece (Alimos, adjacent to Athens, and Mavro Lithari, located further south of Athens). The average WTP per year for the complete removal of macro plastic litter washed ashore by the sea is $€ 0.67$ for Greece ( $€ 8.25$ for Bulgaria). The WTP for removal of cigarette butts left behind by beach visitors is $€ 0.42$ ( $€ 7.06$ ). Results of the study by Hanley et al. (2006) are not directly applicable. They value the improvements to the ecology of the River Wear, in County Durham, England; and the River Clyde, in Central Scotland. The improvements includes absence of litter/debris in 
A Size of litter addressed by countries' measures

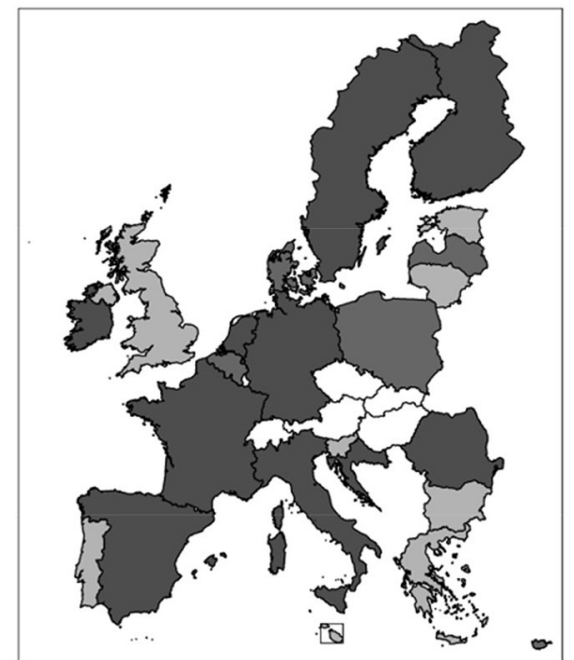

macro litter

micro and macro litter

macro litter and likely micro litter
B Geographical coverage of WTP estimates

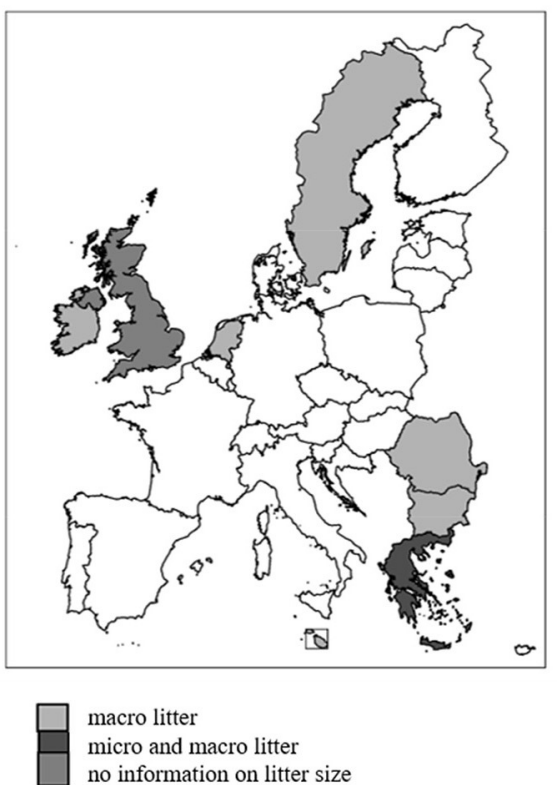

FIGURE 5 | Foci of MSFD Member States' measures and availability of WTP estimates. Detailed information on the EU's assessment with respect to marine litter by country is provided in Table A.4 in the Appendix; Malta is made visible by enlargement (in rectangular box).

the river. The average WTP for such an improvement ranges between $£ 12.07$ and $£ 42.38$ per year in terms of higher water rates payments by households to the local sewerage operator. The study by Latinopoulos et al. (2018) evaluates the effectiveness of a public information campaign on reducing plastic waste in the local coastal/marine environment of the Island of Syros (Greece). The average WTP of residents is highest for biodiversity conservation (€ 55 per year). Annual WTP values for preserving recreational activities, landscape quality and commercial fisheries are much lower and similar in magnitude (€32.5, €29.0, and $€$ 23.6, respectively).

Examining these valuation studies in more detail, we find that it is difficult to infer country-level values from them due to their limits in scope. They are specified to the requirements of the individual study site but not easily transferable to an expost evaluation of measures. Still, these figures can be used to approximate the welfare effect of partial changes. Taking the example of Brouwer et al. (2017) and using a simple back of the envelope calculation for Greece and Bulgaria, the total WTP for the removal of cigarette butts and macro litter on the beach would add up to around $€ 33$ million based on 30 million beach visitors ${ }^{21}$ per year for Greece and $€ 122$ based on 8 million beach visitors $^{22}$ for Bulgaria. The total welfare effect of beach clean-up, however, is likely to be much larger as other benefits of marine

${ }^{21}$ The Number of Arrivals in Tourist Accommodation was 28.7 Million in 2018, Excluding Day-Visitors. Available online at: https://www.statista.com/statistics/ 413222/number-of-arrivals-spent-in-short-stay-accommodation-in-greece/ (accessed July 15, 2020).

${ }^{22}$ The Number of Arrivals in Tourist Accommodation was 7.8 Million in 2018, Excluding Day-Visitors. Available online at: https://www.statista.com/statistics/ litter removal are left out from this calculation. This includes, first, other types of beach litter that will be removed when beaches are cleaned (e.g., cans, food wrappers, and grocery bags). Second, if there is less litter on the beach, this is likely to also reduce the amount of marine litter on the coast, the water column and on the sea floor, litter ingested by marine animals, and micro litter. Third, the calculation only includes beach users and does not take into account the preferences of non-users for marine litter reduction.

Further, results of the valuation studies can be used for benefit transfer to countries for which information is lacking. The transferability of estimates is limited, however, by the correspondence between the study site and the policy site. This includes correspondence in terms of geographical proximity and the socio-economic characteristics of the population (in particular the income levels) but also correspondence in terms of the hypothetical market scenario (level of pollution, type of pollution, payment vehicle, etc.). If the number of studies is large enough, transfer errors can be reduced by applying metaregression analysis to find common trends in the data. So far, however, the number of studies providing WTP estimates is too low to conduct a meta-regression.

\section{CONCLUSIONS}

Faced with the decision how to reduce marine litter, policy makers need to compare the costs and the benefits of individual

413211/number-of-arrivals-spent-in-short-stay-accommodation-in-bulgaria/ (accessed July 15, 2020). 
measures. For the benefits, they need to know the value society attaches to the reduction, i.e., to a cleaner marine environment. Crucially, when weighing their options, only when knowing the benefits decision-makers can determine which policy would yield the largest social welfare and as such could be their preferred choice.

In this paper, we have compared the availability of estimates for the benefits of marine (plastic) litter reduction with the requirements of the MSFD for the EU Member States. While the empirical evidence has increased and become more diverse with respect to countries and sites, the overall evidence is scarce. Of the 22 papers reviewed, only seven studies provide information for eight EU Member States. For the other 15 EU Member States country-specific evidence is not available. Further, especially for micro litter, quantitative evidence on the societal benefits is basically absent. This is despite the attention this type of litter has received in the public debate. However, this disregard is partly reflected in the countries' national programmes of measures. An assessment of the European Commission finds that while all 23 Member States target macro litter, only ten fully address micro litter, four others do so indirectly and nine not at all.

If correspondence between study and policy sites can be assured, benefit estimates from non-EU countries may be transferred to inform EU Member States. Studies that present WTPs per trip (Figure 3) may be particularly suitable, as their results turn out to be relatively independent of the location they focus on and the method they employ. They are also more homogenous in the key characteristics we analyzed than the studies that provide WTP estimates per year (Figure 4). The downside of this relative homogeneity is that they can inform only on descriptor 10.1.1 (litter washed ashore and/or deposited on coastlines) and only be used to proxy specific benefits for the subgroup of users.

Ideally, all descriptors should be considered jointly to account for the interdependencies of marine ecosystems. However, focusing on one descriptor of the MFSD constitutes a first step toward charting the evidence available to inform policy on the benefits of reducing marine litter to society. The empirical evidence, so far, is too patchy to derive country-wide policy implications to the extent necessary to comprehensively conduct the CBAs required by the MFSD. This finding turns out to be valid for both ex-ante as well as ex-post evaluation attempts.

\section{REFERENCES}

Aanesen, M., Falk-Andersson, J., Vondolia, G. K., Borch, T., Navrud, S., and Tinch, D. (2018). Valuing coastal recreation and the visual intrusion from commercial activities in Arctic Norway. Ocean Coast. Manag. 153, 157-167. doi: 10.1016/j.ocecoaman.2017. 12.017

Abate, T. G., Börger, T., Aanesen, M., Falk-Andersson, J., Wyles, K. J., and Beaumont, N. (2020). Valuation of marine plastic pollution in the European Arctic: applying an integrated choice and latent variable model to contingent valuation. Ecol. Econ. 169:106521. doi: 10.1016/j.ecolecon.2019.106521

Alves, B., Benavente, J., and Ferreira, Ó. (2014). Beach users' profile, perceptions and willingness to pay for beach management in Cadiz (SW Spain). J. Coast. Res. 70, 521-526. doi: 10.2112/SI70-088.1
As countries have committed to implementing and evaluating measures to reduce marine litter, the demand for quantitative evidence on the societal benefits is expected to further increase in the future. There are at least three aspects that should be considered in future research to assess these more comprehensively. Firstly, the values non-users attach to reductions of marine litter are understudied, but potentially form an essential part of society's value for it. Secondly, the studies do not account for interdependencies between individual indicators of marine litter reduction. However, measures may affect one or more indicators simultaneously. Thirdly, measures to reduce marine litter are likely to generate co-benefits for other descriptors, such as biological diversity (descriptor 1), sea-floor integrity (descriptor 6), and contaminants in seafood (descriptor 9).

\section{DATA AVAILABILITY STATEMENT}

The original contributions presented in the study are included in the article/supplementary material, further inquiries can be directed to the corresponding author/s.

\section{AUTHOR CONTRIBUTIONS}

IO: investigation. JS: conceptualization, methodology, data analysis, writing-original draft preparation, and writingreviewing and editing. KR: conceptualization, methodology, investigation, data analysis, writing-original draft preparation, and writing-reviewing and editing. All authors contributed to the article and approved the submitted version.

\section{FUNDING}

This work was funded under the EU project CLAIM (Cleaning Litter by developing and Applying Innovative Methods in European Seas) H2020 Grant agreement ID: 774586.

\section{SUPPLEMENTARY MATERIAL}

The Supplementary Material for this article can be found online at: https://www.frontiersin.org/articles/10.3389/fmars. 2021.671326/full\#supplementary-material

Ballance, R., Ryan, P. G., and Turpie, J. (2000). How much is a clean beach worth? The impact of litter on beach users in the Cape Peninsula, South Africa. South Afr. J. Sci. 210-213. doi: 10.10520/AJA00382353_8975

Bateman, I., Carson, R., Day, B., Hanemann, M., Hanley, N., Hett, T., et al. (2002). Economic Valuation With Stated Preference Techniques: A Manual. Cheltenham: Edward Elgar.

Bateman, I. J., Mace, G. M., Fezzi, C., Atkinson, G., and Turner, K. (2011): Economic analysis for ecosystem service assessments. Environ. Resour. Econ. 48, 177-218. doi: 10.1007/s10640-010-9418-x

Beharry-Borg, N., and Scarpa, R. (2010). Valuing quality changes in Caribbean coastal waters for heterogeneous beach visitors. Ecol. Econ. 69, 1124-1139. doi: 10.1016/j.ecolecon.2009.12.007

Bertram, C., Dworak, T., Görlitz, S., Interwies, E., and Rehdanz, K. (2014). Cost-benefit analysis in the context of the EU marine strategy 
framework directive: the case of Germany. Mar. Policy 43, 307-312. doi: 10.1016/j.marpol.2013.06.016

Bertram, C., and Rehdanz, K. (2013). On the environmental effectiveness of the EU marine strategy framework directive. Mar. Policy 38, 25-40. doi: 10.1016/j.marpol.2012.05.016

Birdir, S., Ünal, Ö., Birdir, K., and Williams, A. T. (2013). Willingness to pay as an economic instrument for coastal tourism management: Cases from Mersin, Turkey. Tour. Manag. 36, 279-283. doi: 10.1016/j.tourman.2012.10.020

Blakemore, F., and Williams, A. (2008). british tourists' valuation of a turkish beach using contingent valuation and travel cost methods. J. Coast. Res. 246, 1469-1480. doi: 10.2112/06-0813.1

Blakemore, F. B., Williams, A. T., Coman, C., Micallef, A., and Unal, O. (2002). A comparison of tourist evaluation of beaches in Malta, Romania and Turkey. World Leisure 44, 29-41. doi: 10.1080/04419057.2002.9674268

Brouwer, R., Hadzhiyska, D., Ioakeimidis, C., and Ouderdorp, H. (2017). The social costs of marine litter along European coasts. Ocean Coast. Manag. 138, 38-49. doi: 10.1016/j.ocecoaman.2017.01.011

Cheshire, A. C., Adler, E., Barbière, J., Cohen, Y., Evans, S., Jarayabhand, S., et al. (2009). UNEP/IOC Guidelines on Survey and Monitoring of Marine Litter. Nairobi: United Nations Environment Programme (UNEP)/Intergovernmental Oceanographic Commission (IOC).

Choi, E. C., and Lee, J. S. (2018). The willingness to pay for removing the microplastics in the ocean - the case of Seoul metropolitan area, South Korea. Mar. Policy 93, 93-100. doi: 10.1016/j.marpol.2018 .03 .015

COWI (2010). Scoping Study on the Requirements for Economic Assessment in the MARINE Strategy Framework Directive: Final Report. COWI

Davis, K. J., Burton, M., Rogers, A., Spencer-Cotton, A., and Pandit, R. (2019). Eliciting public values for management of complex marine systems: an integrated choice experiment. Mar. Resour. Econ. 34, 1-21. doi: 10.1086/701303

Enriquez-Acevedo, T., Botero, C. M., Cantero-Rodelo, R., Pertuz, A., and Suarez, A. (2018). Willingness to pay for beach ecosystem services: the case study of three colombian beaches. Ocean Coast. Manag. 161, 96-104. doi: 10.1016/j.ocecoaman.2018.04.025

European Commission (2017). Report From the Commission to the European Parliament and the Council: Assessing the Member States' Monitoring Programmes Under the Marine Strategy Framework Directive. SWD(2017) 1 Final/COM(2017) 3 Final. Brussels: European Commission.

European Commission (2018a). Commission Staff Working Document Accompanying the Document 'Report From the Commission to the European Parliament and the Council Assessing Member States' Programmes of Measures Under the Marine Strategy Framework Directive'. SWD(2018) 393 final/COM(2018) 562 final. Brussels: European Commission.

European Commission (2018b). Report From the Commission to the European Parliament and the Council Assessing the Member States' Programmes of Measures Under the Marine Strategy Framework Directive. SWD(2018) 393 Final. Brussels: European Commission.

European Commission (2019). Commission Staff Working Document. Marine Strategy Framework Directive - Assessment of Programmes of Measures for Denmark, Estonia, Greece, Croatia, Lithuania, Romania and Slovenia. SWP(2019) 510 final. Brussels: European Commission.

Freeman, A. M., Herriges, J. A., and Kling, C. L. (2014). The Measurement of Environmental and Resource Values: Theory and Methods. Abingdon, VA; New York, NY: RFF Press; Routledge.

Hanley, N., Wright, R. E., and Alvarez-Farizo, B. (2006). Estimating the economic value of improvements in river ecology using choice experiments: an application to the water framework directive. J. Environ. Manag. 78, 183-193. doi: 10.1016/j.jenvman.2005.05.001

Hynes, S., Tinch, D., and Hanley, N. (2013). Valuing improvements to coastal waters using choice experiments: an application to revisions of the EU bathing waters directive. Mar. Policy 40, 137-144. doi: 10.1016/j.marpol.2012.12.035

Kaul, S., Boyle, K. J., Kuminoff, N. V., Parmeter, C. F., and Pope, J. C. (2013). What can we learn from benefit transfer errors? Evidence from 20 years of research on convergent validity. J. Environ. Econ. Manag. 66, 90-104. doi: 10.1016/j.jeem.2013.03.001

Krelling, A. P., Souza, M. M., Williams, A. T., and Turra, A. (2017). Transboundary movement of marine litter in an estuarine gradient: evaluating sources and sinks using hydrodynamic modelling and ground truthing estimates. Mar. Pollut. Bull. 119, 48-63. doi: 10.1016/j.marpolbul.2017. 03.034

Latinopoulos, D., Mentis, C., and Bithas, K. (2018). The impact of a public information campaign on preferences for marine environmental protection. The case of plastic waste. Mar. Pollut. Bull. 131, 151-162. doi: 10.1016/j.marpolbul.2018. 04.002

Leggett, C. G., Scherer, N., Haab, T. C., Bailey, R., Landrum, J. P., and Domanski, A. (2018). Assessing the economic benefits of reductions in marine debris at southern California beaches: a random utility travel cost model. Mar. Resour. Econ. 33, 133-153. doi: 10.1086/697152

Loomis, J., and Santiago, L. (2013). Economic valuation of beach quality improvements: comparing incremental attribute values estimated from two stated preference valuation methods. Coast. Manag. 41, 75-86. doi: 10.1080/08920753.2012.749754

Morgan, R. (1999). A novel, user-based rating system for tourist beaches. Tou. Manag. 20, 393-410.

Östberg, K., Håkansson, C., Hasselström, L., and Bostedt, G. (2013). Benefit transfer for environmental improvements in coastal areas: general versus bestfitting models. Can. J. Agric. Econ. 61, 239-258. doi: 10.1111/cjag.12010

Östberg, K., Hasselström, L., and Håkansson, C. (2012). Non-market valuation of the coastal environment-uniting political aims, ecological and economic knowledge. J. Environ. Manag. 110, 166-178. doi: 10.1016/j.jenvman.2012.06.012

Schuhmann, P. W., Bass, B. E., Casey, J. F., and Gill, D. A. (2016). Visitor preferences and willingness to pay for coastal attributes in Barbados. Ocean Coast. Manage. 134, 240-250. doi: 10.1016/j.ocecoaman.2016.09.020

Shen, M., Di, M., Xie, H., and Li, C. (2019). The social costs of marine litter along the east China sea: evidence from ten coastal scenic spots of zhejiang province, China. Sustainability 11:1807. doi: 10.3390/su11061807

Smith, V. K., Zhang, X., and Palmquist, R. B. (1997). Marine debris, beach quality, and non-market values. Environ. Resour. Econ. 10, 223-247.

Talpur, M. A., Koetse, M. J., and Brouwer, R. (2018). Accounting for implicit and explicit payment vehicles in a discrete choice experiment. J. Environ. Econ. Policy 7, 363-385. doi: 10.1080/21606544.2018. 1450789

TEEB (2010). The Economics of Ecosystems and Biodiversity: Ecological and Economic Foundations. Kumar, Pushpam (ed.). London: Earthscan.

Ünal, Ö., and Williams, A. T. (1999). "Beach visits and willingness to pay: Çeşme Peninsula, Turkey," in MEDCOAST 99 - EMECS 99 Joint Conference, Land-Ocean Interactions: Managing Coastal Ecosystems, ed E. Özhan (Antalya). World Bank (2020). World Development Indicators. Available online at: https:// data.worldbank.org/ (accessed April 1, 2020).

Zhai, G., and Suzuki, T. (2008). Public willingness to pay for environmental management, risk reduction and economic development: evidence from Tianjin, China. China Econ. Rev. 19, 551-566. doi: 10.1016/j.chieco.2008. 08.001

Conflict of Interest: The authors declare that the research was conducted in the absence of any commercial or financial relationships that could be construed as a potential conflict of interest.

Publisher's Note: All claims expressed in this article are solely those of the authors and do not necessarily represent those of their affiliated organizations, or those of the publisher, the editors and the reviewers. Any product that may be evaluated in this article, or claim that may be made by its manufacturer, is not guaranteed or endorsed by the publisher.

Copyright (c) 2021 Stoever, Rehdanz and Okoli. This is an open-access article distributed under the terms of the Creative Commons Attribution License (CC BY). The use, distribution or reproduction in other forums is permitted, provided the original author(s) and the copyright owner(s) are credited and that the original publication in this journal is cited, in accordance with accepted academic practice. No use, distribution or reproduction is permitted which does not comply with these terms. 